\author{
Classification \\ Physics Abstracts \\ $61.40 \mathrm{~K}$
}

\title{
Small angle neutron scattering by semi-dilute solutions of polyelectrolyte
}

\author{
M. Nierlich, C. E. Williams, F. Boué, J. P. Cotton, M. Daoud, B. Farnoux, G. Jannink \\ Laboratoire Léon-Brillouin, B.P. no 2, 91190 Gif sur Yvette, France \\ C. Picot
}

CRM, 6, rue Boussingault, 67083 Strasbourg, France

M. Moan, C. Wolff

Laboratoire d'Hydrodynamique Moléculaire, Faculté des Sciences, 29283 Brest, France

M. Rinaudo

CERMAV, Cedex 53, 38041 Grenoble, France

and P. G. de Gennes

Collège de France, 75231 Paris Cedex 05, France

(Reçu le 26 décembre 1978, accepté le 20 mars 1979)

Résumé. - Nous examinons les résultats d'expérience de diffusion de neutrons aux petits angles

$$
\left(10^{-2}<q<2 \times 10^{-1} \AA^{-1}\right)
$$

par des solutions de sulfonate de polystyrène dans l'eau pour des concentrations supérieures à $0,5 \times 10^{-2} \mathrm{~g} \cdot \mathrm{cm}^{-3}$. Avec de l'eau ultra pure, l'absence de diffusion centrale et la présence d'un maximum pour les plus grandes valeurs de $q$ caractérisent la fonction de diffusion $S(q)$. Les deux effets étudiés, variation de la concentration en polyions et addition de sel, conduisent à des résultats différents : la position du maximum varie avec la concentration de polyions alors qu'avec l'addition de sel, on note l'apparition de diffusion centrale et disparition du maximum.

Abstract. - Solutions of polyelectrolyte are studied by small angle neutron scattering for $c>0.5 \times 10^{-2} \mathrm{~g} . \mathrm{cm}^{-3}$. The function $S(q)$ is characterized by a small value of $S(q \rightarrow 0)$ and one broad maximum for higher $q$ 's

$$
\left(10^{-2}<q<2 \times 10^{-1} \AA^{-1}\right) \text {. }
$$

The effect of polyion concentration and addition of salt are studied : the position of the maximum varies with polyion concentration and when salt is added to the solution, forward scattering appears and the peak vanishes.

A few studies by light scattering of salt free polyelectrolyte solutions have already explored the vicinity of zero scattering angle and have shown an increase of the intensity with increasing scattering angle [1, 2]. More recently, neutron scattering experiments in dilute solutions have explored a much greater range of correlation lengths $[3,4,5]$. This paper presents a study of concentrated solutions of polyelectrolyte, where chains overlap. We examine the $q$ dependence of the scattering law $S(q)$ and its variation with the concentration of polyions and addition of salt. In order to get reproducible results, the solutions must be prepared with great care, eliminating small ionic impurities in the solvent.

1. Experimental details. - We have used the experimental facilities of the Léon-Brillouin Laboratory at Saclay. The scattered intensity was recorded 
with an $X-Y$ multidetector of $128 \times 128$ cells with $1 \mathrm{~cm}^{2}$ area. The momentum transfer $q$ varies from $10^{-2}$ to $2 \times 10^{-1} \AA^{-1} \quad(q=4 \pi / \lambda \sin \theta / 2, \theta$ the scattering angle, $\lambda$ the wavelength; $\lambda=4.82 \AA$, $\Delta \lambda / \lambda=0.02)$. We study solutions of deuterated sodium polystyrene sulfonate $\left[\left(\mathrm{C}_{8} \mathrm{D}_{7} \mathrm{SO}_{3} \mathrm{Na}\right)_{N}\right]$ in ultra pure water (resistivity $=18 \mathrm{M} \Omega \cdot \mathrm{cm}^{-1}$ ) contained in quartz cells.

The polystyrene is sulfonated by mixing liquid $\mathrm{SO}_{3}$ and a PS- $\mathrm{CHCl}_{3}$ solution at $-50{ }^{\circ} \mathrm{C}$; it is then neutralized by a $\mathrm{NaOH}$ solution. This method is known to yield a high degree of sulfonation : in our case $99.5 \%$. We consider then, that all the monomers are charged ; the average minimum distance between neighbouring charges is about $2.5 \AA$.

The experimental concentrations, from $0.5 \times 10^{-2}$ to $23 \times 10^{-2}$ g. cm ${ }^{-3}$ are higher than the concentration $c^{*}$ above which the stretched chains cannot rotate freely i.e.

$$
c^{*}=\frac{M}{\mathcal{N} L^{3}}
$$

$M=$ molecular weight,

$\mathcal{N}=$ Avogadro's number

$L=$ maximum length of the stretched chain.

The characteristics of the polymer are summarized in table $\mathrm{I}$.

Table I.

Molecular weight

Degree of polymerization

Maximum length

Overlap concentration

Polydispersity of pa-

rent polystyrene

$$
\begin{array}{cc}
M_{\mathrm{w}} & 72000 \\
N & 343 \\
L=N a & 857 \AA \\
c^{*} & 2 \times 10^{-4} \mathrm{~g} \cdot \mathrm{cm}^{-3} \\
\frac{M_{\mathrm{w}}}{M_{\mathrm{n}}} & <1.2
\end{array}
$$

It should be noted that for our samples,

$$
c=0.5 \times 10^{-2} \mathrm{~g} . \mathrm{cm}^{-3}
$$

is the lowest possible experimental concentration required for an acceptable signal-to-noise ratio. Thus we deal only with semi-dilute solutions.

2. Results. - 2.1 SALt fREe POLYeleCtrolyte solutions. - When no simple electrolyte is added to the solutions of polyelectrolyte, the observed scattering function $S(q)$ is characterized by two features (Fig. 1) :

- a very small value of $S(q)$ at the limit of $q \rightarrow 0$; - and a broad maximum for $q$ values between $10^{-2}$ and $2 \times 10^{-1} \AA^{-1}$.

The small value of $S(q \rightarrow 0)$ occurs only with pure solutions (i.e. with a minimum of foreign small ionic impurities). As an example, figure 2 shows the great difference in the scattering curve of pure and impure solutions.

This weak forward scattering for salt-free solutions gives experimental evidence of the osmotic incom-

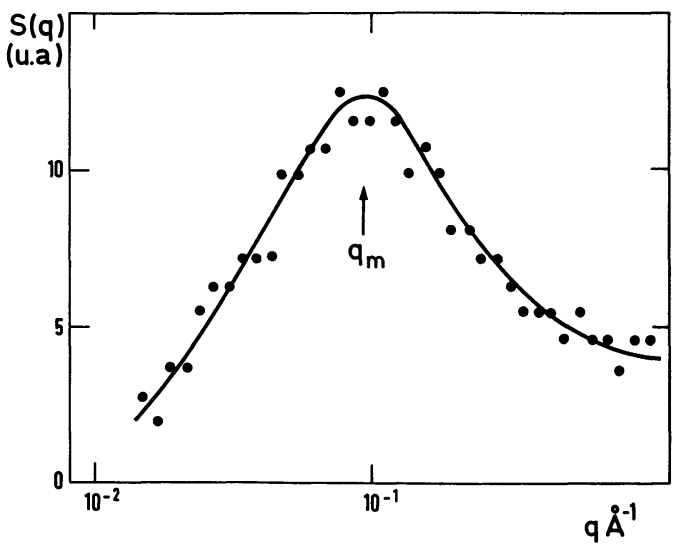

Fig. 1. - Scattered intensity by a solution of deuterated sodium polystyrene sulfonate (Na $\mathrm{PSS}_{\mathrm{D}}$ ) in water as a function of $q$; concentration $=4.76 \times 10^{-2} \mathrm{~g} \cdot \mathrm{cm}^{-3}$.

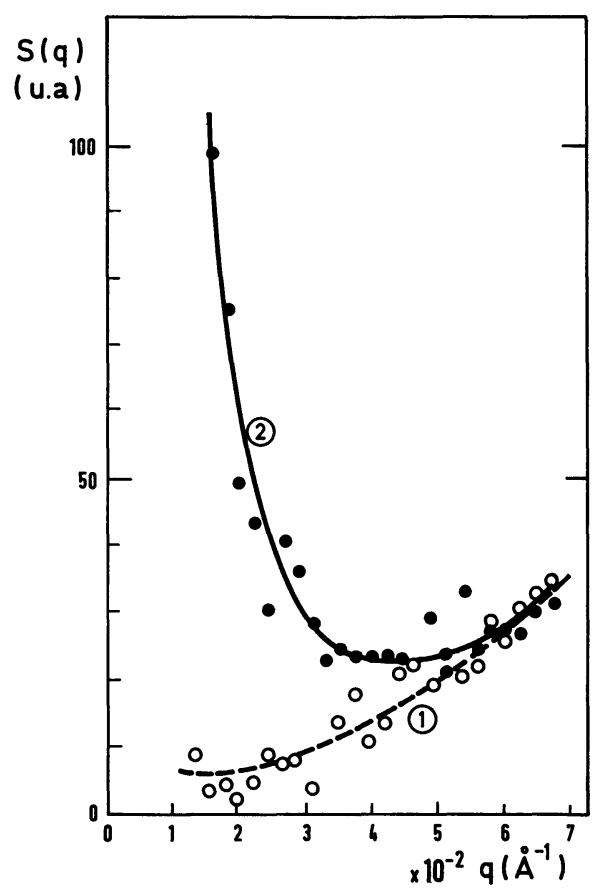

Fig. 2. - Scattered intensity by : 1) a solution of deuterated sodium polystyrene sulfonate in ultra pure $\mathrm{H}_{2} \mathrm{O}$.

$$
c=1.96 \times 10^{-2} \mathrm{~g} . \mathrm{cm}^{-3} ;
$$

2) a solution of hydrogenated sodium polystyrene sulfonate in $\mathrm{D}_{2} \mathrm{O}$ $c=1.96 \times 10^{-2} \mathrm{~g} . \mathrm{cm}^{-3}$. With ultra pure $\mathrm{H}_{2} \mathrm{O}$ (curve 1$) S(q \rightarrow 0)$ is small whereas for $\mathrm{D}_{2} \mathrm{O}$ solutions (curve 2) in which the concentration of cation impurities measured by mass spectrometry is about $10^{-4} \mathrm{~g} \cdot \mathrm{cm}^{-3}, S(q \rightarrow 0)$ is much higher.

pressibility of polyelectrolyte solutions. Indeed, the osmotic compressibility is related to the scattered intensity extrapolated at zero angle [6, 7]. A simplified relation can be written as [8] :

$$
S(q \rightarrow 0)=T c \frac{\partial c}{\partial \pi}
$$

$c=$ polyion concentration,

$\pi=$ osmotic pressure. 
The small experimental value of $S(q \rightarrow 0)$ shows the small compressibility of polyelectrolyte solutions and is well explained by the high osmotic pressure of these solutions [9].

One broad maximum of the scattering function, whose position varies with concentration, appears for all concentrations (Fig. 3). (For

$$
c=23 \times 10^{-2} \mathrm{~g} \cdot \mathrm{cm}^{3},
$$

the maximum intensity is outside the experimental range.) The $q$ values corresponding to the maximum intensity vary as $c^{0.5}$ for the lower concentrations ; however, a small departure from this law is observed for the two higher concentrations studied $\left(9.09 \times 10^{-2}\right.$ and $13.04 \times 10^{-2} \mathrm{~g} . \mathrm{cm}^{3}$ ) (Fig. 4). The exponent of 0.5 agrees with the two theoretical models, a lattice model of aligned rigid rods [10] and an isotropic model where the conformation of a chain is assumed to be a Gaussian succession of rigid segments [11].

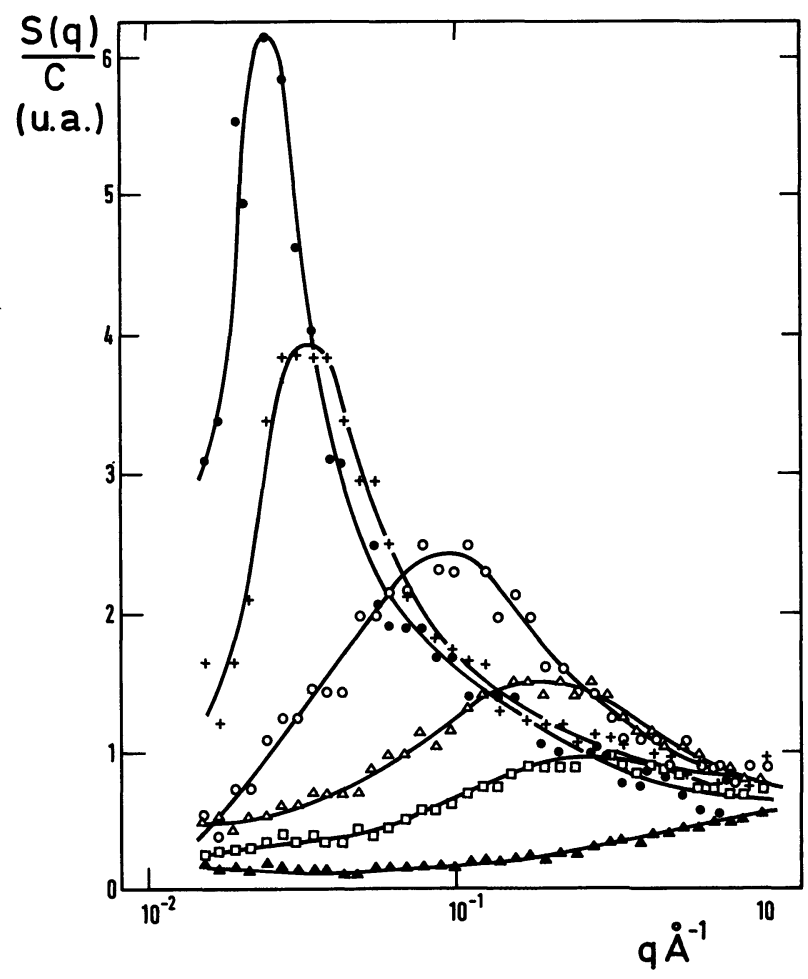

Fig. 3. - Scattered intensity per monomer of a solution of Na PSS $_{D}\left(M_{\mathrm{w}}=72000\right)$ in $\mathrm{H}_{2} \mathrm{O}$ versus polymer concentration.

- $c=10^{-2} \mathrm{~g} \cdot \mathrm{cm}^{-3} ;+1.96 \times 10^{-2} \mathrm{~g} \cdot \mathrm{cm}^{-3}$;

○ $4.76 \times 10^{-2} \mathrm{~g} . \mathrm{cm}^{-3} ; \Delta 9.09 \times 10^{-2} \mathrm{~g} . \mathrm{cm}^{-3} ;$

$\square 13.04 \times 10^{-2} \mathrm{~g} . \mathrm{cm}^{-3} ; \Delta 23 \times 10^{-2} \mathrm{~g} . \mathrm{cm}^{-3}$.

This peak is due to interference effects between different chains, as shown by another experiment to be described elsewhere [12]. This second experiment, based on the intensity scattered by labelled chains, allows the separation of intrachain from interchain signals.

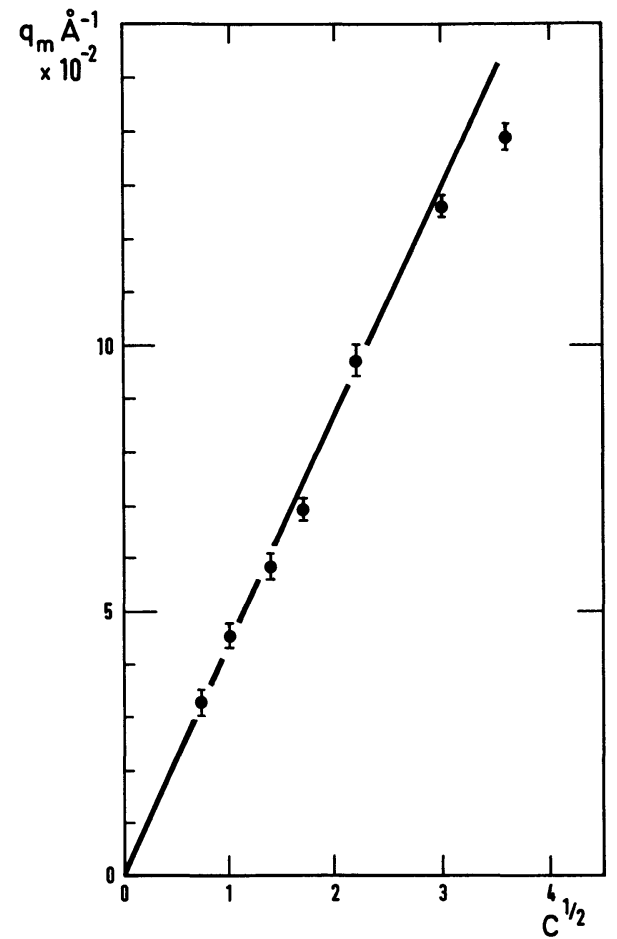

Fig. 4. - Plot of $q_{\mathrm{m}}$ values at different concentrations $c$ as a function of the square root of $c$.

Table II.

$\begin{array}{ccc}\begin{array}{c}c \times 10^{-2} \\ \mathrm{~g} . \mathrm{cm}^{-3}\end{array} & \begin{array}{c}q_{\mathrm{m}} \times 10^{-1} \\ \text { in. } \AA^{-1}\end{array} & \begin{array}{c}q_{\mathrm{m}}^{-1} \\ \text { in } \AA\end{array} \\ - & - & - \\ 0.5 & 0.33 & 30.3 \\ 1 & 0.45 & 22.2 \\ 1.96 & 0.58 & 17.2 \\ 2.91 & 0.68 & 14.6 \\ 4.76 & 0.97 & 10.3 \\ 9.09 & 1.26 & 7.9 \\ 13.04 & 1.39 & 7.2\end{array}$

2.2 Polyelectrolyte solutions With salt. Addition of a simple electrolyte to the solutions screens the electrostatic forces and reduces the osmotic pressure $[13,14,15]$. For neutron scattering, this gives a large increase of the intensity at $q \rightarrow 0$.

Figure 5 shows changes in the measured intensity with salt concentration $c_{\mathrm{s}}$ at fixed polymer concentration $c_{\mathrm{p}}$. The $q$ value corresponding to the peak $\left(q_{\mathrm{m}}\right)$ does not change with $c_{\mathrm{s}}$ : only the region $q<q_{\mathrm{m}}$ is affected, the region $q>q_{\mathrm{m}}$ remaining nearly constant. For a certain value of $c_{\mathrm{s}}\left(c_{\mathrm{s}} / c_{\mathrm{p}}=0.33\right)$, the peak disappears and for higher values of $c_{\mathrm{s}}$, the scattered intensity becomes similar to a neutral polymer behaviour.

3. Conclusion. - These neutron scattering experiments show that the effects of polyion concentration and of salt are completely different. Both the increase 


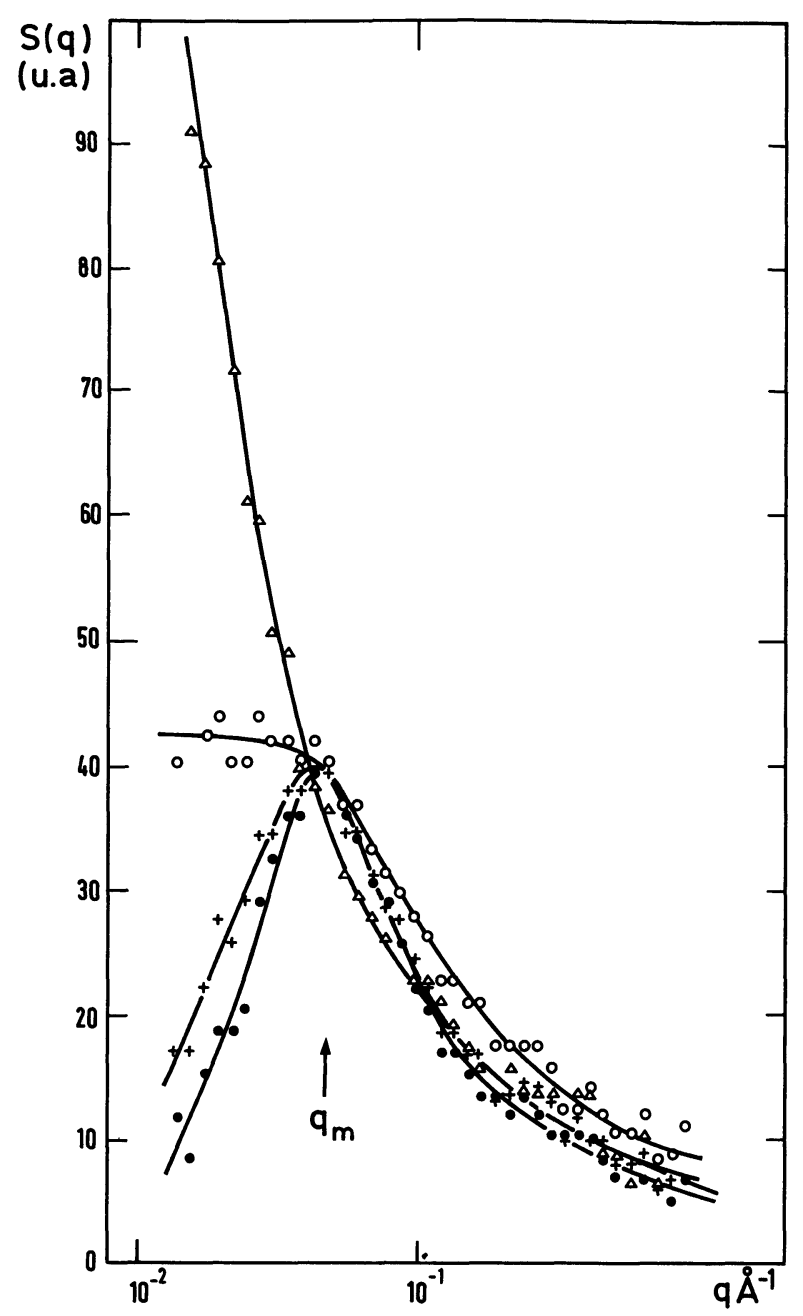

Fig. 5. - Plots of $S(q)$ versus $q$ for $\mathrm{Na} \mathrm{PSS}_{\mathrm{D}}$ in aqueous $\mathrm{NaBr}$ solutions. The polymer concentration is $2.9 \times 10^{-2} \mathrm{~g} \cdot \mathrm{cm}^{-3}$. The salt concentration $c_{\mathbf{s}}$ varies from :

$$
\begin{aligned}
& O \text { to } 3 \times 10^{-2} \mathrm{~g} \cdot \mathrm{cm}^{-3} ; \\
& c_{\mathrm{s}}=0 ;+10^{-3} \mathrm{~g} \cdot \mathrm{cm}^{-3} ; \\
& 5 \times 10^{-3} \mathrm{~g} \cdot \mathrm{cm}^{-3} ; \Delta 3 \times 10^{-2} \mathrm{~g} \cdot \mathrm{cm}^{-3} \text {. }
\end{aligned}
$$

in polyion and in salt concentration screen the Coulomb interactions and modify the structure of the solutions but there is a strong difference in the $q$ dependence.

The variation of concentration has a considerable effect on the position of the broad peak whereas the addition of salt does not affect the position but only the shape of the maximum until it gradually vanishes. The present experiments were still preliminary and a more systematic study of the influence of polyion concentrations, molecular weight, and addition of simple electrolyte has now been started. It should lead to a more detailed picture of the conformations and organization of the polyions.

\section{References}

[1] Doty, P., Steiner, R., J. Chem. Phys. 20 (1952) 85.

[2] Alexandrowicz, Z., J. Polym. Sci. 43 (1960) 337.

[3] Moan, M., Wolff, C., Ober, R., Chem. Phys. Lett. 28 (1974) 505.

[4] Moan, M., Wolff, C., Ober, R., Polymer 16 (1975) 776.

[5] Cotton, J. P., Moan, M., J. Physique Lett. 37 (1976) L-75 ; Moan, M., J. Appl. Crystallogr. 11 (1978) 519.

[6] Stockmayer, W. H., J. Chem. Phys. 18 (1950) 58.

[7] KIRKwood, J. G., Buff, F. P., J. Chem. Phys. 19 (1951) 774.

[8] EgelstafF, P. A., An introduction to the liquid state (Academic Press) 1967.

[9] Katchalsky, A., AleXandrowicz, Z., Kedem, O., Chemical physics of ionic solutions (Conway and Barradas, E. Wiley) 1966.

[10] Lirsov. S., Katchalsky, A., J. Polym. Sci. 13 (1954) 43.

[11] De Gennes, P. G. et al., J. Physique 37 (1976) 1461.

[12] Williams, C. E. et al., J. Polym. Sci., Polym. Lett. Ed., to be published.

[13] TANFORD, C., Physical chemistry of Macromolecules (Ed. Wiley) 1967.

[14] NierLich, M. et al., Proceeding of the IVth Intern. Conference on Small Angle Scattering. Gatlinburg 1977, J. Appl. Crystallogr. (1978).

[15] Takahashi, A., Kato, N., Nagasawa, M., J. Phys. Chem. 74 (1970) 944. 